\title{
Investigation of kinetics of phenyl radicals with ethyl formate in the gas phase using cavity ring-down spectroscopy and theoretical methodologies
}

\author{
Koushik Mondal ${ }^{1} \cdot$ Rajakumar Balla ${ }^{1}$
}

Received: 5 December 2020 / Accepted: 6 May 2021 / Published online: 1 July 2021

(c) The Author(s), under exclusive licence to European Photochemistry Association, European Society for Photobiology 2021

\begin{abstract}
The gas-phase kinetics of phenyl radical $\left(\mathrm{C}_{6} \mathrm{H}_{5}\right)$ with ethyl formate $\left(\mathrm{HCO}_{2} \mathrm{Et}, \mathrm{EF}\right)$ was investigated experimentally using ultrasensitive laser-based cavity ring-down spectroscopy (CRDS). Phenyl radicals were generated by photolyzing nitrosobenzene $\left(\mathrm{C}_{6} \mathrm{H}_{5} \mathrm{NO}\right)$ at $248 \mathrm{~nm}$ and thereby probed at $504.8 \mathrm{~nm}$. The rate coefficients for the (phenyl radical $+\mathrm{EF}$ ) reaction were investigated between the temperatures of 260 and $361 \mathrm{~K}$ and at a pressure of 61 Torr with nitrogen $\left(\mathrm{N}_{2}\right)$ as diluent. The temperaturedependent Arrhenius expression for the test reaction was obtained as: $\mathrm{k}_{\text {phenyl+EF }}^{\mathrm{Expt} 260-361 \mathrm{~K}}=(1.20 \pm 0.16) \times 10^{-13} \exp [-$ $(435.6 \pm 50.0) / \mathrm{T}] \mathrm{cm}^{3}$ molecule ${ }^{-1} \mathrm{~s}^{-1}$ and the rate coefficient at room temperature was measured out to be: $\mathrm{k}_{\text {phenyl+EF }}^{\text {Expt } 298 \mathrm{~K}}$ $=(4.54 \pm 0.42) \times 10^{-14} \mathrm{~cm}^{3}$ molecule ${ }^{-1} \mathrm{~s}^{-1}$. The effects of pressure and laser fluence on the kinetics of the test reaction were found to be negligible within the experimental uncertainties. To complement the experimental findings, kinetics for the reaction of phenyl radicals with EF was investigated theoretically using Canonical Variational Transition State Theory (CVT) with Small Curvature Tunnelling (SCT) at CCSD(T)/cc-pVDZ//B3LYP/6-31+G(d,p) level of theory in the temperatures between 200 and $400 \mathrm{~K}$. The theoretically calculated rate coefficients for the title reaction were expressed in the Arrhenius form as: $\mathrm{k}_{\text {phenyl+EF }}^{\text {Theor }, 200-400 \mathrm{~K}}=$ $(1.48 \pm 0.56) \times 10^{-38} \times \mathrm{T}^{8.47} \times \exp [(2431.3 \pm 322.0) / \mathrm{T}] \mathrm{cm}^{3}$ molecule ${ }^{-1} \mathrm{~s}^{-1}$ and the corresponding rate coefficient at room temperature was calculated to be: $\mathrm{k}_{\mathrm{phenyl}+\mathrm{EF}}^{\text {Theory }}=4.91 \times 10^{-14} \mathrm{~cm}^{3}$ molecule $\mathrm{e}^{-1} \mathrm{~s}^{-1}$. A very good agreement was observed between the experimentally measured and theoretically calculated rate coefficients at $298 \mathrm{~K}$. Thermochemical parameters as well as branching ratios for the reaction of (phenyl radical $+\mathrm{EF}$ ) are also discussed in this manuscript.
\end{abstract}

Keywords Cavity ring-down spectroscopy · Gas-phase kinetics · Phenyl radical · Biodiesel $\cdot$ Thermochemistry $\cdot$ Branching ratio

\section{Introduction}

In today's world of modernisation, there has been a drastic increase in the energy demand compared to that of the preindustrial era. There has been a progressive depletion in the oil reserves of the planet Earth because of the extensive use of fossil fuels such as petroleum, diesel, gasoline, etc. Moreover, the extensive fossil fuel emissions have also attributed to the poor air quality, especially in the metropolitan areas and industrial zones. The conventional fossil fuels majorly contain aromatic hydrocarbon components such as benzene,

Rajakumar Balla

rajakumar@iitm.ac.in

1 Department of Chemistry, Indian Institute of Technology Madras, Chennai 600036, India toluene, anthracene, xylene, phenanthrene, etc. [1-4]. Upon combustion of these fuels, there occurs the formation of aryl radicals that constitute the major parts of the polycyclic aromatic hydrocarbons (PAHs) which are considered to be potential mutagens and carcinogens [5-7]. Phenyl radical $\left(\mathrm{C}_{6} \mathrm{H}_{5}\right)$ is the simplest aromatic radical and it is one of the most significant precursors responsible for the formation of PAHs in the atmosphere. These formed PAHs subsequently lead to the formation of soot particles and contribute to air pollution and global warming [8,9]. Hence, kinetic investigation of phenyl radical with species of atmospheric interest is not only highly necessary to better understand the chemistry of PAH formation, but also for predicting the kinetic behaviours of similar resonance stabilized radicals.

Along with the formation of soot particles, these PAHs also leads to the generation of secondary organic aerosols (SOAs) 
in the Earth's atmosphere [8]. SOAs represent a significant proportion of aerosols contained in the troposphere [10]. In this regard, the nations across the globe are trying to enforce stricter emission control policies to reduce the usage of conventional fossil fuels as well as their subsequent harmful greenhouse gas emissions into the atmosphere. In this current scenario, there is a high need for phasing out petroleum-based gasoline fuels and moving out towards alternative synthetic fuels which not only have higher combustion efficiency but also lead to more greener emissions. Biodiesels have emerged in this present scenario, as the most preferred and renewable hydrocarbon liquid fuels to meet these requirements $[11,12]$. Generally, they are produced from vegetable oils, animal fats, algae, etc. and consist of long-chain fatty acid esters. These oxygenated biodiesels are primarily composed of mixtures of saturated and unsaturated methyl, ethyl or propyl esters [13]. Ethyl formate $\left(\mathrm{HCO}_{2} \mathrm{Et}, \mathrm{EF}\right)$ is the simplest model of ethyl esters which is considered to be a biodiesel surrogate [14]. EF is used in various applications such as food flavourings, perfumes, etc. It occurs naturally in fruits (e.g., raspberries) and gets released because of the atmospheric oxidation of ethers. Moreover, $\mathrm{EF}$ has been identified in the dust clouds of Sagittarius B2, an interstellar space in the Milky Way Galaxy [15]. Thus, considering its importance in combustion, atmospheric and even in interstellar chemistry, a gas-phase kinetic investigation of phenyl radicals with $\mathrm{EF}$ would not only be helpful in understanding atmospheric oxidation of EF by phenyl radicals, but also to better comprehend the chemistry of long-chain fatty acid ethyl esters in the biodiesels.

To the best of our knowledge, there is no report in the literature to date, regarding the kinetics of phenyl radicals with $\mathrm{EF}$. Hence it is a first attempt to decipher the title reaction kinetics. In the present work, gas-phase kinetics of the test reaction has been investigated using ultrasensitive cavity ring-down spectroscopy (CRDS) and computational techniques, in the conditions relevant to the troposphere. The kinetics for the reaction of phenyl radical $+\mathrm{EF}$ was investigated in the temperatures between 260 and $361 \mathrm{~K}$ and at 61 Torr of total pressure using our in-built laser-based CRDS setup. The dependency of the rate coefficients with the experimental pressures and the photolysis laser fluences were also verified. Moreover, the kinetics of phenyl radical $+\mathrm{EF}$ ) was investigated theoretically between the temperatures 200 and $400 \mathrm{~K}$ employing Canonical Variational Transition state theory (CVT) along with the Small Curvature Tunneling (SCT) corrections at $\mathrm{CCSD}(\mathrm{T}) / \mathrm{cc}-\mathrm{pVDZ} / /$ B3LYP/6-31+G(d,p). In addition, the thermodynamic parameters as well as the branching ratios of the individual reaction channels were calculated.

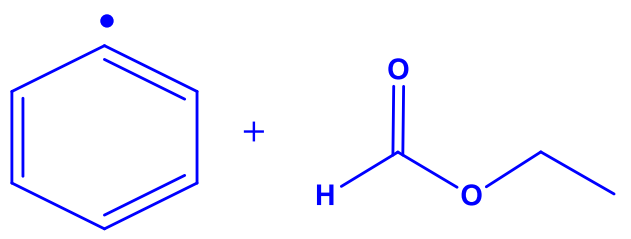

\section{Methodology}

\subsection{Experimental details}

In-built pulsed laser photolysis CRDS apparatus along with the experimental methodology have been described in detail elsewhere [16, 17]. Therefore, only a brief summary of the experimental method used in this work is presented here. Figure 1 shows the schematic illustration of the experimental setup used in this work. The setup consists of a $0.86 \mathrm{~m}$ long flow reactor made of borosilicate Pyrex glass. A high finesse linear optical cavity (Fébry-Parot) was established by careful alignment $\left(\sim 0^{\circ}\right.$ angle) between the two-high reflectance (HR) mirrors (CRD Optics; $\mathrm{R}=0.99995$ at $500 \mathrm{~nm}$ ) with a radius of curvature and diameter of $1 \mathrm{~m}$ and $2.54 \mathrm{~cm}$, respectively. These two HR mirrors were housed over custom made mechanical mounts to integrate with the Pyrex reaction cell. Throughout the course of experiments, the HR mirrors were purged with a continuous and minute flow of $\mathrm{N}_{2}$ to prevent its deterioration because of unwanted condensation or decomposition of samples over them. In the centre of this cell, a double-walled Pyrex made reaction cell was mounted at a direction perpendicular to the axis of the cavity. A heated or cooled fluid (H5 thermal oil) was allowed to flow through the outer jacket of this middle reaction zone to maintain the required experimental temperatures. A calibrated type $\mathrm{K}$ thermocouple (Chromel-Alumel) was attached underneath the reaction zone to accurately maintain the required temperatures within a maximum of $\pm 2 \mathrm{~K}$ during the course of experiments. On both ends of the double-jacketed reaction zone, AR-coated $248 \mathrm{~nm}$ windows (fused silica) were fitted to allow the photolysis beam to pass through. The flows of the gaseous mixture (precursor, reactant and diluent) were allowed to enter from one end of the reaction zone and pumped out from the other end to maintain a continuous flow. A diaphragm-based capacitance manometer (MKS Baratron; 1000 Torr) was connected at the mid of the reaction zone to accurately measure the total pressure within the CRDS cell.

The in-built CRDS facility includes two pulsed lasers: a photolysis laser for the generation of the radicals and a probe laser for probing the generated radicals transitions to the upper electronic excited states. A $\mathrm{KrF}$ excimer laser (Coherent Compex Pro) with an average photon density of $1-2 \times 10^{16}$ photons $\mathrm{cm}^{-2}$ pulse ${ }^{-1}$ was employed to photolyze 


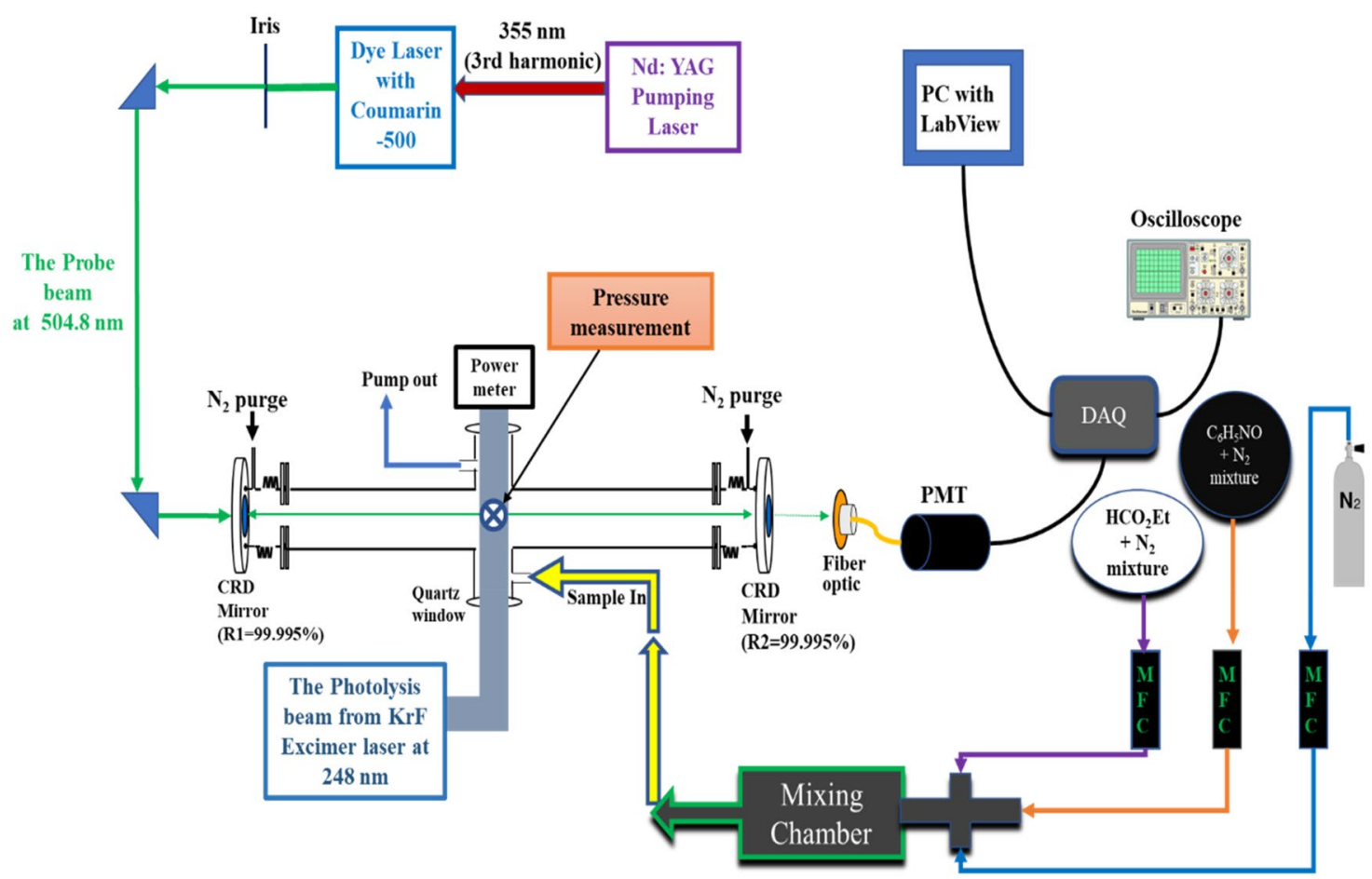

Fig. 1 Schematic representation of the pulsed laser photolysis cavity ring-down spectroscopy (CRDS) setup used for studying the kinetics of phenyl radicals with EF. $M F C$ mass flow controller, $P M T$ photomultiplier tube, $D A Q$ data acquisition card

the precursor nitrosobenzene $\left(\mathrm{C}_{6} \mathrm{H}_{5} \mathrm{NO}\right)$ to generate phenyl radicals at $248 \mathrm{~nm}$ (1). The photolysis beam was resized to a diameter of $3 \mathrm{~cm}$ using an iris and injected into the reaction zone through one of the AR-coated windows. A tunable dye laser (Lioptec LiopStar VN) operated with Coumarin 500 dye, was used as the probe laser to probe the generated phenyl radicals at $504.8 \mathrm{~nm}$ (2)corresponding to a ${ }^{2} \mathrm{~B}_{1} \leftarrow{ }^{2} \mathrm{~A}_{1}$ transition for a $\pi \rightarrow \mathrm{n}$ excitation within the aromatic framework [18].

$\mathrm{C}_{6} \mathrm{H}_{5} \mathrm{NO} \stackrel{h v, 248 n m}{\longrightarrow} \cdot \mathrm{C}_{6} \mathrm{H}_{5}$

$\mathrm{C}_{6} \mathrm{H}_{5} \stackrel{h v, 504.8 n m}{\longrightarrow}\left(\mathrm{C}_{6} \mathrm{H}_{5}\right)^{*}$

The dye laser was optically pumped by the third harmonic $(355 \mathrm{~nm})$ of a Nd:YAG laser (1064 nm; Continuum Surelite III). The probe laser beam was allowed to enter through one of the HR mirrors, at an angle of $90^{\circ}$ with respect to the photolysis laser beam. For the kinetic measurements, a digital delay generator (SRS DG645) was employed to vary the time delay between the photolysis and probe lasers during the course of experiments. Both the photolysis and probe lasers were operated at a laser frequency of $2 \mathrm{~Hz}$ throughout the measurements.
A collimated lens (Thorlabs F220SMA-532) attached with a fiber optical cable (Thorlabs M25L01) was employed to collect the light leaking from the rear mirror of the optical cavity. For the detection of the photons, a photomultiplier tube (PMT; Hamamatsu Photonics R943-02), was used. A data acquisition card (DAQ; 16-bit NI PXIe-6124; $2 \mathrm{GS} / \mathrm{s}$ ) was used to generate the waveforms and to convert the analog output from the cavity into a digital data. LabVIEW 16.0 (NI) program suite was used for controlling the instruments as well as the integration of the acquired data by DAQ into the personal computer (PC). A four-channel digital oscilloscope (Tektronix TDS 2024B; $200 \mathrm{MHz}, 2 \mathrm{GS} / \mathrm{s}$ ) was used for the visualization of the ring-down profiles. All the wavelengths were measured in the air using a commercial spectrometer (Avantes AvaSpec-ULS2048L StarLine). A calibrated power meter (Coherent J-25MUV-248 sensor head with FieldMaxII-TOP) was used for monitoring the photolysis laser fluences during the course of experiments.

The individual flows as well as the mixing ratios of the precursor (nitrosobenzene), reactant (EF), diluent and purge $\left(\mathrm{N}_{2}\right)$ were regulated via calibrated mass flow controllers (MFCs; Sierra Instruments Top-Trak). A cylindrical mixing chamber was used for the proper mixing of the precursor, reactant and diluent before being loaded into the CRDS 
reaction zone using an in-built gas handling system. A vacuum pump was used to maintain the required total pressure within the CRDS cell for a stable and continuous flow, during the course of experiments. EF was purified with repeated cycles of freeze-pump-thaw before loading into the glass bulbs and was diluted with $\mathrm{N}_{2}$. The vapours of nitrosobenzene were introduced into the CRDS reaction zone via the mixing chamber with the help of the carrier gas $\mathrm{N}_{2}$.

A typical ring-down waveform was averaged for at least 25 laser shots for each of the spectral points at a particular delay time. An exponential fit was applied to the decay in light intensity within the cavity to obtain the ring-down times which is basically defined as the time taken for the intensity to decay to (1/e) of its initial intensity. The obtained ring-down times were converted to the absorption coefficient $\left(\propto, \mathrm{cm}^{-1}\right)$ by the following relation:

$\propto=[$ phenyl $] \times \sigma_{\text {phenyl }}(\lambda)=\frac{\mathrm{R}_{\mathrm{L}}}{\mathrm{c}}\left[\frac{1}{\tau(\lambda)}-\frac{1}{\tau_{0}(\lambda)}\right]$,

where $\tau_{0}$ and $\tau$ are the ring-down times (s) before and after the photolysis laser pulse, respectively; $\sigma_{\text {phenyl }}$ denotes the absorption cross-section $\left(\mathrm{cm}^{2}\right.$ molecule $\left.{ }^{-1}\right)$ of phenyl radicals at a particular wavelength; [phenyl] represent the number density (molecules $\mathrm{cm}^{-3}$ ) of phenyl radicals; $\mathrm{c}$ is the speed of light $\left(\mathrm{cm} \mathrm{s}^{-1}\right)$ and $\mathrm{R}_{\mathrm{L}}$ is the ratio of the length of the cavity $(86 \mathrm{~cm})$ and effective length of absorption $(4.1 \mathrm{~cm})$ at the reaction zone.

To investigate the kinetics of phenyl radicals with EF experimentally, pseudo first-order condition was employed where the concentration of the reactant (EF) was kept three orders of magnitude higher than that of the precursor concentration. The reaction time which is basically the time delay between photolysis and probe laser, was varied from 0 to $1 \mathrm{~ms}$ for each concentration of EF. At each of the studied temperatures, the kinetics for the title reaction was investigated for six different concentrations of $\mathrm{EF}$ and subsequently, the title reaction kinetics was measured at six distinct temperatures (vide infra). A constant concentration of the precursor was maintained throughout the course of experiments. The number densities of the EF and nitrosobenzene were calculated from the mole fractions of their respective and total gas flows (in sccm) through the MFCs and the total pressure within the CRDS cell. Throughout the course of experiments, the phenyl radical concentration was maintained in the range of $8-9 \times 10^{11}$ radicals $\mathrm{cm}^{-3}$. The concentration of the generated phenyl radicals was calculated from the photolysis laser fluence, quantum yield, flows and absorption cross-section of nitrosobenzene at $248 \mathrm{~nm}$. The ring-down times were measured both in the absence and presence of the photolysis laser to obtain $\tau_{0}$ and $\tau$, respectively, to measure the kinetics of the title reaction.

\subsection{Chemicals}

EF (99.9\% purity) was purchased from Sigma Aldrich. Solid nitrosobenzene (96\%; Sigma Aldrich) was recrystallized from ethanol and vacuum dried subsequently. It was kept under evacuation overnight before being carried into the CRDS reaction zone via $\mathrm{N}_{2}$. Nitrogen (UHP 99.995\%; Bhuruka Gases, India) was employed without any further purification.

\subsection{Computational details}

Quantum chemical calculations for the reaction of phenyl radicals with EF was computed using the Gaussian 16 program suite [19]. Geometric optimization of all the reactants $\left(\mathrm{C}_{6} \mathrm{H}_{5}\right.$ and $\left.\mathrm{EF}\right)$, pre-reactive complexes (RCs), transition states (TSs) and products (Ps) were performed at B3LYP density functional theory with Pople's basis set $6-31+G(d, p)$ [20-22]. The normal-mode harmonic vibrational frequencies for all the stationary points located on the potential energy surface were obtained at B3LYP/6-31 + G(d,p) level of theory. No imaginary frequency was identified for all the reactants, RCs and products, whereas each of the TSs corresponding to the abstraction of $\mathrm{H}$ atom by phenyl radical was recognized with one imaginary frequency. For the visualization of the optimized geometries and normal modes of all the stationary points, GaussView 6.0 [23] was used. To ensure that the obtained TSs connect both the reactants and products along the minimum energy pathway (MEP), intrinsic reaction coordinate (IRC) calculations $[24,25]$ were executed at B3LYP/6-31+G(d,p) level of theory and are depicted in the supplementary information (SI). The IRC calculations also ensured that all the obtained TSs follow distinct MEPs.

To obtain accurate kinetic parameters, estimation of the barrier heights needs to be performed with high accuracy and for this purpose, interpolated single point energy (ISPE) calculations for all the stationary points were refined with single, double and triple perturbative excitations method [CCSD(T)] in combination with correlation-consistent polarized valence double $\zeta$ basis set (cc-pVDZ) [26-28]. For all the stationary points involved in the reaction of phenyl radicals with EF, T1 diagnostic test was conducted during the ISPE calculations and are tabulated in the SI (Table S1). All the values were found to be less than 0.02 and 0.045 for closed and openshell systems, respectively, which implies that there is no such requirement for the multireference calculations [29].

The kinetics of the reaction (phenyl $+\mathrm{EF}$ ) was explored theoretically using canonical variational transition state theory along with small curvature tunnelling (CVT/SCT) corrections [30-35]. The rate coefficients of the title reaction were calculated by employing Polyrate 2008 in combination with Gaussrate 2009A program suites [36, 37] in 
the temperature range of 200-400 K. Hessian-based PageMcIver predictor-corrector integrator was employed with a step size of $0.01 \AA$ to obtain the MEP for the mass-weighted reaction coordinate, $\mathrm{s}$, within the limits of -1.0 to $+1.0 \AA$. For every step, a Hessian matrix was identified and the harmonic frequencies were scaled by a standard factor of 0.964 along the MEP, for a more precise determination of kinetic as well as thermochemical parameters [38].

The CVT/SCT rate coefficients were calculated using the following relations where the rate coefficients corresponding to the generalized TSs were minimized by changing the dividing surface of the TSs along the reaction coordinate

$\mathrm{k}^{\mathrm{GT}}(\mathrm{T}, \mathrm{s})=\mathrm{L} \sigma\left(\frac{\mathrm{k}_{\mathrm{B}} \mathrm{T}}{\mathrm{h}}\right)\left[\frac{\mathrm{Q}^{\mathrm{GT}}(\mathrm{T}, \mathrm{s})}{\mathrm{Q}^{\mathrm{R}}(\mathrm{T})}\right] \exp \left[-\frac{\mathrm{V}_{\mathrm{MEP}}(\mathrm{s})}{\mathrm{k}_{\mathrm{B}} \mathrm{T}}\right]$,

$\mathrm{k}^{\mathrm{CVT}}(\mathrm{T})=\min _{\mathrm{s}}\left[\mathrm{k}^{\mathrm{GT}}(\mathrm{T}, \mathrm{s})\right]=\mathrm{k}^{\mathrm{GT}}\left[\mathrm{T}, \mathrm{s}^{\mathrm{CVT}}(\mathrm{T})\right]$,

where $\mathrm{k}^{\mathrm{GT}}$ and $\mathrm{k}^{\mathrm{CVT}}$ denotes the generalized and CVT rate coefficients, respectively; $\mathrm{L}$ indicates degeneracy of the reaction path; $\sigma$ denotes the ratio of the symmetry numbers of TSs and reactants. $\mathrm{k}_{\mathrm{B}}$, $\mathrm{T}$ and $\mathrm{h}$ refer to the standard notations of Boltzmann's constant $\left(\mathrm{J} \mathrm{K}^{-1}\right)$, temperature $(\mathrm{K})$ and Planck's constant $\left(\mathrm{J}\right.$ s), respectively. $\mathrm{Q}^{\mathrm{GT}}$ and $\mathrm{Q}^{\mathrm{R}}$ denotes the partition functions for the generalized TS and the reactants (R) at $\mathrm{s}$, respectively. $\mathrm{V}_{\mathrm{MEP}}$ indicates the potential energy of the generalized TS at s; $\mathrm{s}^{\mathrm{CVT}}$ is the reaction coordinate at which the CVT dividing surface between the reactants and products was identified. The SCT corrected rate coefficients $\left(\mathrm{k}^{\mathrm{CVT} / \mathrm{SCT}}\right)$ for the reaction of (phenyl radical $+\mathrm{EF}$ ) were obtained via multiplication of the CVT rate coefficient $\left(\mathrm{k}^{\mathrm{CVT}}\right)$ with the $\mathrm{T}$ dependent transmission coefficient for $\operatorname{SCT}\left(\kappa^{\mathrm{SCT}}\right)$, as

$\mathrm{k}^{\mathrm{CVT} / \mathrm{SCT}}(\mathrm{T})=\kappa^{\mathrm{SCT}}(\mathrm{T}) \times \mathrm{k}^{\mathrm{CVT}}(\mathrm{T})$.

Finally, the CVT/SCT rate coefficients obtained in the temperature range of $200-400 \mathrm{~K}$ for the title reaction at CCSD(T)/cc-pVDZ//B3LYP/6-31+G(d,p) level of theory, were fitted to the three parameter modified Arrhenius equation-

$k(T)=A T^{n} \exp \left[-\frac{E_{a}}{R T}\right]$.

\section{Results and discussion}

\subsection{Experimental measurements for kinetics of (phenyl radical + EF) reaction}

The kinetics of phenyl radicals with EF was investigated in the gas phase using CRDS in the temperatures between 260 and $361 \mathrm{~K}$ at a total pressure of $(61 \pm 2)$ Torr with $\mathrm{N}_{2}$. Phenyl radicals were generated in situ in the CRDS reaction zone via photolysis of nitrosobenzene of which concentration was maintained at $(6-7) \times 10^{13}$ molecules $\mathrm{cm}^{-3}$. As discussed in our previous publication ${ }^{18}$, nitrosobenzene is considered to be the cleanest as well as the best precursor to yield phenyl radicals at $248 \mathrm{~nm}$ as it is a having higher absorption cross-section $\left[\sigma_{\mathrm{C}_{6} \mathrm{H}_{5} \mathrm{NO}}^{24.04 \mathrm{~nm}}=1.22 \times 10^{-17} \mathrm{~cm}^{2}\right.$ molecule $\left.{ }^{-1}\right]$ at the photolysis wavelength $(248 \mathrm{~nm}) \mathrm{com}$ pared to other precursors and hence, was chosen for this study. The average photolysis laser fluence was kept at $5.3 \mathrm{~mJ} \mathrm{~cm}^{-2}$ pulse ${ }^{-1}$ during the course of experiments. Both the lasers were maintained at a repetition rate of $2 \mathrm{~Hz}$. The concentration of the generated phenyl radicals was calculated to be $(8-9) \times 10^{11}$ radicals $\mathrm{cm}^{-3}$ at $(61 \pm 2)$ Torr of pressure and $5.3 \mathrm{~mJ} \mathrm{~cm}^{-2}$ pulse $^{-1}$ of average laser fluence.

At a particular temperature, the delay time between the photolysis and probe lasers was varied from 0 to $1 \mathrm{~ms}$ with the interval of $100 \mu$ s for a particular concentration of the reactant, i.e. EF. This delay time is basically the measure of the reaction time between phenyl radicals and EF. The concentrations of EF were maintained within the range of $1.64-4.63 \times 10^{16}$ molecules $\mathrm{cm}^{-3}$ during the course of experiments. Pseudo first-order rate coefficients were measured for six different concentrations of $\mathrm{EF}$ at each temperature. The relationship between the delay time and photon decay time holds as follows [16]:

$\ln \left[\frac{1}{\tau}-\frac{1}{\tau_{0}}\right]=\mathrm{D}-\mathrm{k}_{\mathrm{p}} \mathrm{t}$,

$\mathrm{D}=\ln \left(\frac{\sigma_{\text {phenyl }} \times \mathrm{c} \times[\text { phenyl }]_{0}}{\mathrm{R}_{\mathrm{L}}}\right)$,

where $t$ is the delay time between the photolysis and probe laser (s); D is a constant containing time-independent parameters (Eq. 9); $\mathrm{k}_{\mathrm{p}}$ denotes the pseudo-first-order rate coefficient $\left(\mathrm{s}^{-1}\right)$ which was obtained from the slope of the plot of $\ln \left(\frac{1}{\tau}-\frac{1}{\tau_{0}}\right)$ vs $t$ (according to Eq. 8). Figure 2 depicts the experimentally measured pseudo first-order plot for the kinetics of the reaction (phenyl radical $+\mathrm{EF}$ ) at 61 Torr and $298 \mathrm{~K}$. The concentrations of $\mathrm{EF}$ were progressively increased starting from $\mathrm{C}_{1}$ to $\mathrm{C}_{6}\left(\mathrm{C}_{1}<\mathrm{C}_{2}<\mathrm{C}_{3}<\mathrm{C}_{4}<\mathrm{C}_{5}<\mathrm{C}_{6}\right)$ within a particular range. For all the temperatures, the concentration of $\mathrm{EF}$ was varied from a minimum of $1.64 \times 10^{16}$ to a maximum of $4.63 \times 10^{16}$ molecules $\mathrm{cm}^{-3}$ for six different concentrations by varying its flow. The magnitudes of $k_{p}$ were found to increase steadily upon going from $\mathrm{C}_{1}$ to $\mathrm{C}_{6}$ at a particular temperature. All the kinetic measurements were conducted up to $1 \mathrm{~ms}$ of time delay as beyond this reaction time, the validity of the pseudo first-order behaviour was 


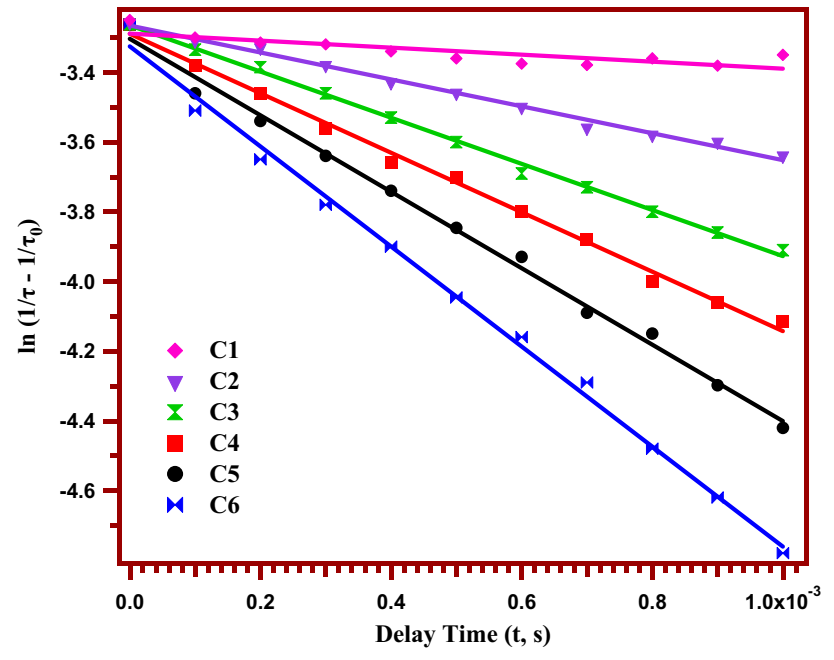

Fig. 2 Pseudo first-order plot for the reaction between phenyl radicals and $\mathrm{EF}$ at six distinct concentrations of $\mathrm{EF}: \mathrm{C}_{1}=1.67 \times 10^{16}$; $\mathrm{C}_{2}=2.23 \times 10^{16} ; \mathrm{C}_{3}=2.79 \times 10^{16} ; \mathrm{C}_{4}=3.33 \times 10^{16} ; \mathrm{C}_{5}=3.88 \times 10^{16}$ and $\mathrm{C}_{6}=4.54 \times 10^{16}$ molecules $\mathrm{cm}^{-3}$ at $(298 \pm 2) \mathrm{K}$ and $(61 \pm 2)$ Torr pressure with $\mathrm{N}_{2}$. The reaction times (i.e. delays) were varied from 0 to $1 \mathrm{~ms}$ with an interim of $100 \mu \mathrm{s}$ at $2 \mathrm{~Hz}$

found to be absent for phenyl radicals, as discussed previously [17].

The obtained pseudo first-order rate coefficient $\left(\mathrm{k}_{\mathrm{p}}\right)$ at a particular temperature follows a linear relationship with the concentration of EF, [EF], as

$k_{p}=k_{d}+k_{2}[E F]$,

where, $\mathrm{k}_{2}$ denotes the bimolecular rate coefficient $\left(\mathrm{cm}^{3}\right.$ molecule $\mathrm{e}^{-1} \mathrm{~s}^{-1}$ ) for the reaction of (phenyl radical $+\mathrm{EF}$ ) and it was procured from the slope of the plot of $k_{p} v s[E F]$ for a particular temperature, following Eqn. 10. Figure 3 depicts the second-order plot for the kinetics of the title reaction in the temperature range of 260-361 K. The intercept of the plot is denoted by $k_{d}$ which is basically the apparent first-order decay coefficient $\left(\mathrm{s}^{-1}\right)$ of phenyl radicals which is attributed to the diffusion of the radicals away from the probing zone and possibility of some side reactions, e.g., phenyl + phenyl or phenyl $+\mathrm{NO}$, etc. during the course of experiments. An average $\mathrm{k}_{\mathrm{d}}$ value of $(116.55 \pm 13.31) \mathrm{s}^{-1}$ was measured in the studied temperature range and this low value of $k_{d}$ indicates a negligible impact of diffusion and side reactions over the kinetics of the test reaction.

At a total pressure of 61 Torr and an average photolysis laser fluence of $5.3 \mathrm{~mJ} \mathrm{~cm}^{-2}$ pulse $^{-1}$, the kinetics of the reaction (phenyl radical $+\mathrm{EF}$ ) was investigated at the temperatures of 260, 279, 298, 320, 342 and $361( \pm 2) \mathrm{K}$ using CRDS. The experimentally measured rate coefficients for the title reaction are depicted in Table 1 . Reproducibility of the experimentally measured rate coefficients was ensured by repeating the

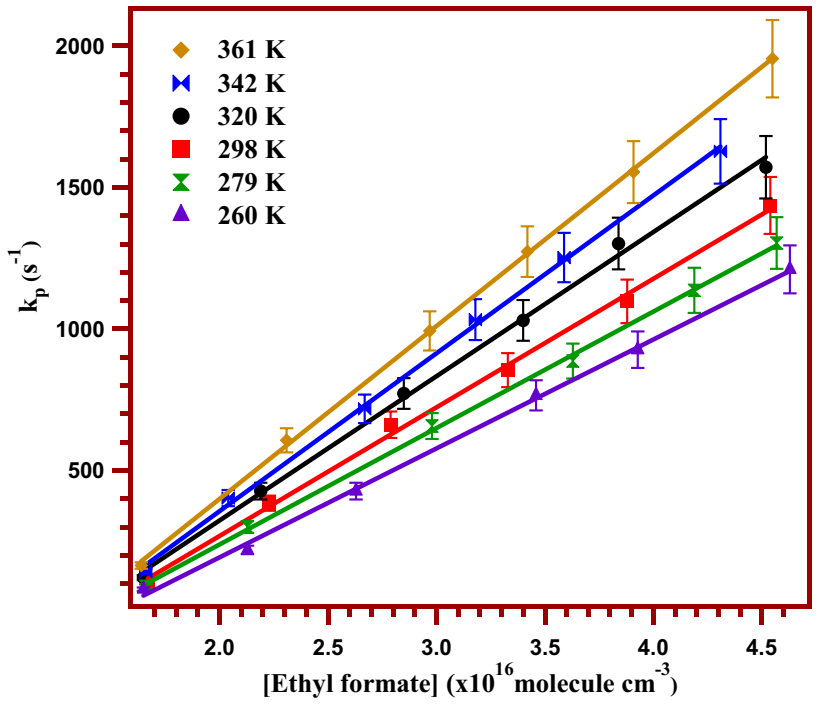

Fig. 3 Variation of the pseudo first-order rate coefficients $\left(k_{\mathrm{p}}\right)$ with respect to the concentrations of $\mathrm{EF}$ for the reaction of (phenyl radi$\mathrm{cal}+\mathrm{EF})$ at $260,279,298,320,342$ and $361( \pm 2) \mathrm{K}$. The bimolecular rate coefficients $\left(k_{2}\right)$ of the test reaction at each temperature was obtained from their respective slopes. The vertical bars represent errors in $2 \sigma$

measurements at least three times at any particular temperature. The rate coefficient for the test reaction was measured o u t to be $\mathrm{k}_{\text {phenyl+EF }}^{\text {Exp, } 298 \mathrm{~K}}=(4.54 \pm 0.42) \times 10^{-14} \mathrm{~cm}^{3}$ molecule $\mathrm{e}^{-1} \mathrm{~s}^{-1}$ at room temperature $(298 \mathrm{~K})$ and $(61 \pm 2)$ Torr of total pressure with $\mathrm{N}_{2}$.

Using linear least squares method, the experimentally measured rate coefficients were fitted to obtain an Arrhenius equation in the studied temperature range of $260-361 \mathrm{~K}$ and the corresponding plot is depicted in Fig. 8. The T dependent Arrhenius expression for the reaction between phenyl radicals and $\mathrm{EF}$, was obtained as-

Table 1 Experimentally measured rate coefficients for the reaction between phenyl radicals and EF between 260 and $361 \mathrm{~K}$ at a total pressure of 61 Torr with $\mathrm{N}_{2}$ using CRDS. The uncertainties are denoted at $2 \sigma$

\begin{tabular}{lll}
\hline $\begin{array}{l}\text { Temperature } \\
( \pm 2 \mathrm{~K})\end{array}$ & $\begin{array}{l}{[\mathrm{EF}]} \\
\times 10^{-16} \text { molecule } \mathrm{cm}^{-3}\end{array}$ & $\begin{array}{l}\mathrm{k}_{2} \text { (Experi- } \\
\text { ment) } \\
\times 10^{14} \mathrm{~cm}^{3} \\
\text { molecule }^{-1} \mathrm{~s}^{-1}\end{array}$ \\
\hline 260 & $1.65-4.63$ & $3.85 \pm 0.41$ \\
279 & $1.66-4.57$ & $4.11 \pm 0.35$ \\
298 & $1.67-4.54$ & $4.54 \pm 0.42$ \\
320 & $1.65-4.52$ & $5.09 \pm 0.47$ \\
342 & $1.66-4.31$ & $5.58 \pm 0.52$ \\
361 & $1.64-4.55$ & $6.10 \pm 0.58$ \\
\hline
\end{tabular}




$$
\begin{aligned}
\mathrm{k}_{\mathrm{phenyl}+\mathrm{EF}}^{\text {Expt } 260-361 \mathrm{~K}}= & (1.20 \pm 0.16) \times 10^{-13} \\
& \times \exp \left[\frac{-(435.6 \pm 50.0)}{\mathrm{T}}\right] \mathrm{cm}^{3} \text { molecule }^{-1} \mathrm{~s}^{-1}
\end{aligned}
$$

A positive temperature dependency in the kinetics for the reaction between phenyl radicals and EF was detected in the studied temperature range.

\subsection{Effect of pressure on (phenyl radical + EF) kinetics}

The total pressure within the CRDS reaction cell was maintained at $(61 \pm 2)$ Torr during the measurement of the kinetics of the reaction of phenyl radicals with EF. In order to investigate the effect of pressures on the kinetics of the title reaction, a pressure dependency study was performed. The pressure was varied from a minimum of 43 to a maximum of $128( \pm 2)$ Torr at room temperature, keeping all other parameters the same. All the gas flows and experimental conditions were kept same except the diluent $\mathrm{N}_{2}$ flow which was varied to maintain the required total pressure in the cell.

The average photolysis laser fluence was maintained at $5.3 \mathrm{~mJ} \mathrm{~cm}^{-2}$ pulse $\mathrm{m}^{-1}$ at $2 \mathrm{~Hz}$. The rate coefficients for the reaction (phenyl radical $+E F$ ) were measured at the experimental pressures of 43, 61, 84, 106 and 128 Torr with $\mathrm{N}_{2}$ at room temperature and no dependency was observed in the kinetics of the title reaction. The measured rate coefficients have been tabulated in Table 2 and its variation with the experimental pressures is depicted in Fig. 4. It can be inferred from the obtained data that the rate coefficients were found to be indistinguishable within the experimental uncertainties and therefore, the kinetics of the title reaction doesn't show any dependency with the experimental pressures in the studied pressure range.

Table 2 The variation of the rate coefficients for the reaction of (phenyl radical +EF) at an average photolysis laser fluence of $5.3 \mathrm{~mJ} \mathrm{~cm} \mathrm{culse}^{-1}$

\begin{tabular}{ll}
\hline $\begin{array}{l}\text { Total experi- } \\
\text { mental pres- } \\
\text { sure } \\
( \pm 2 \text { Torr })\end{array}$ & $\begin{array}{l}\mathrm{k}_{2} \text { (Experi- } \\
\text { ment) } \\
\times 10^{14} \mathrm{~cm}^{3} \\
\text { molecule }^{-1} \mathrm{~s}^{-1}\end{array}$ \\
\hline 43 & $4.47 \pm 0.39$ \\
61 & $4.54 \pm 0.42$ \\
84 & $4.51 \pm 0.46$ \\
106 & $4.59 \pm 0.48$ \\
128 & $4.57 \pm 0.43$ \\
\hline
\end{tabular}

The total pressures were varied by controlling the flows of $\mathrm{N}_{2}$, keeping all other flows constant at $298 \mathrm{~K}$

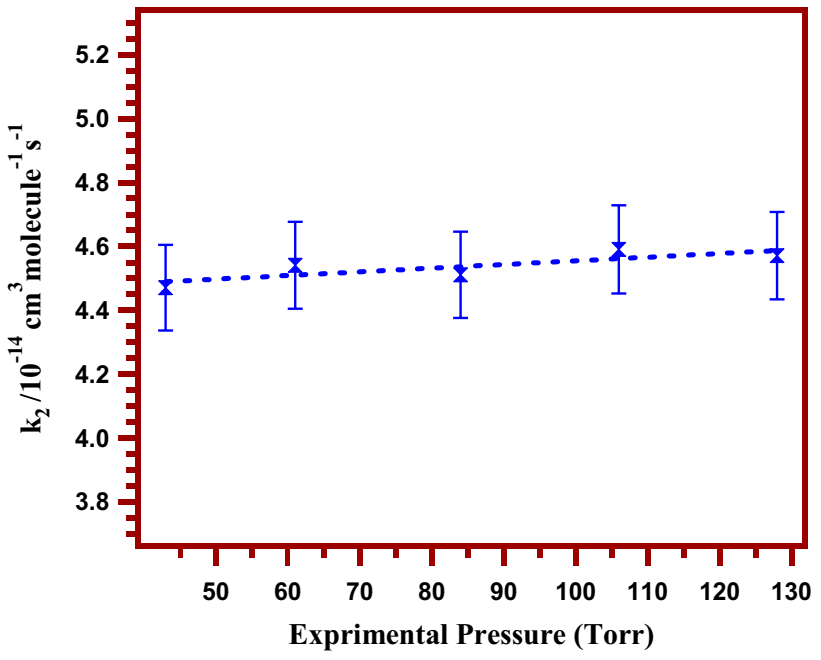

Fig. 4 Plot depicting the variation of the bimolecular rate coefficient $\left(k_{2}\right)$ for the reaction of (phenyl radical $+\mathrm{EF}$ ) with the total experimental pressures ranging from 43-128 $( \pm 2)$ Torr at an average photolysis laser fluence of $5.3 \mathrm{~mJ} \mathrm{~cm}^{-2}$ pulse $^{-1}$ and $298 \mathrm{~K}$. The dashed line is a linear fit

\subsection{Effect of fluence on (phenyl radical + EF) kinetics}

Laser fluence $\left(\mathrm{F} ; \mathrm{J} \mathrm{cm}^{-2}\right.$ pulse $\left.{ }^{-1}\right)$ is defined as the amount of laser energy delivered in a single pulse per effective focal spot area. At a particular wavelength $(\lambda)$ and precursor concentration ([pre]; molecules $\mathrm{cm}^{-3}$ ), the generated radical concentration ([radical]; radicals $\mathrm{cm}^{-3}$ ) is directly proportional to the photolysis laser fluence, as-

$[$ radical $]=[$ pre $] \times \sigma_{\text {pre }}(\lambda) \times \varphi \times \mathrm{F}$

Here, $\sigma_{\text {pre }}(\lambda)$ denotes the absorption cross-section of the precursor at the photolysis wavelength and $\varphi$ is the quantum yield. Therefore, higher is the laser fluence, higher is the photon density delivered per unit area and higher is the number density of the radicals that gets generated from the precursor at the reaction zone. The radical concentration, in turn, is directly proportional to the absorption loss rate in CRDS i.e., $\left(\frac{1}{\tau}-\frac{1}{\tau_{0}}\right)$ at a particular wavelength, as-

$[$ radical $]=\frac{\mathrm{L}}{\mathrm{c} \mathrm{L}_{S} \sigma_{\text {radical }}(\lambda)}\left(\frac{1}{\tau}-\frac{1}{\tau_{0}}\right)$

where $\mathrm{c}, \mathrm{L}$ and $\mathrm{L}_{\mathrm{S}}$ denotes speed of light, length of the cavity and effective length of absorption respectively and they are all constants for a particular experimental setup. $\sigma_{\text {radical }}(\lambda)$ is the absorption cross-section of the generated radicals at its probe wavelength and it is constant for a particular radical at a particular wavelength. If kinetics of a radical-molecule reaction has dependency with the laser fluence, then rate coefficient of the reaction may vary quite significantly with the change in laser fluence during the course of experiments. 
So, in order to understand whether the gas phase kinetics of the reaction between phenyl radical and EF is having any dependency over the photolysis laser fluence or not, the fluence dependency studies were performed for the title reaction.

All the kinetic measurements for the reaction of phenyl radicals with $\mathrm{EF}$ were performed by maintaining an average photolysis laser fluence of $5.3 \mathrm{~mJ} \mathrm{~cm} \mathrm{~cm}^{-2}$ pulse $^{-1}$ throughout the experiments. In order to find out how the kinetics of the title reaction varies with the laser fluence, a fluence dependency study was performed. The average photolysis laser fluences were varied from a minimum of 5.3 to up to $12.0 \mathrm{~mJ} \mathrm{~cm}^{-2}$ pulse $^{-1}$ by varying the discharge voltage of the excimer laser at $2 \mathrm{~Hz}$. All the parameters and experimental conditions were kept the same. At $298 \mathrm{~K}$, the kinetics of the reaction (phenyl radical $+\mathrm{EF}$ ) was investigated at various laser fluences at a total pressure of $(61 \pm 2)$ Torr with $\mathrm{N}_{2}$.

The measured rate coefficients along with the corresponding laser fluences, have been tabulated in Table 3 and are shown in Fig. 5. A slight increment in the rate coefficients of the title reaction was observed as the photolysis laser fluences were varied from 5.3 to up to $12.0 \mathrm{~mJ} \mathrm{~cm}{ }^{-2}$ pulse $^{-1}$, but the variation was only within a maximum of $5 \%$ and well within the experimental uncertainties. Therefore, it is concluded that the kinetics for the reaction between phenyl radicals and EF does not show any dependency on photolysis laser fluence in the studied fluence range at 61 Torr and $298 \mathrm{~K}$. This slight increase in rate coefficients should be attributed to the increase in the phenyl radical number density at the reaction zone with the increase in the laser fluence.

\subsection{Theoretical calculations for kinetics of (phenyl radical + EF) reaction}

Kinetics for the reaction of phenyl radicals with EF was investigated theoretically by using CVT/SCT methodology at $\operatorname{CCSD}(\mathrm{T}) / \mathrm{cc}-\mathrm{pVDZ} / / \mathrm{B} 3 \mathrm{LYP} / 6-31+\mathrm{G}(\mathrm{d}, \mathrm{p})$ level of theory. The rate coefficients of the title reaction were calculated

Table 3 The variation of rate coefficients for the reaction of phenyl radical with EF with the photolysis laser fluences at $298 \mathrm{~K}$ and 61 Torr of total pressure

\begin{tabular}{lc}
\hline $\begin{array}{l}\text { Average photolysis laser fluence } \\
\left(\mathrm{mJ} \mathrm{cm}^{-2} \text { pulse }^{-1}\right)\end{array}$ & $\begin{array}{l}\mathrm{k}_{2} \text { (Experi- } \\
\mathrm{ment}) \\
\times 10^{14} \mathrm{~cm}^{3} \\
\text { molecule }^{-1} \mathrm{~s}^{-1}\end{array}$ \\
\hline 5.3 & $4.54 \pm 0.33$ \\
7.5 & $4.57 \pm 0.34$ \\
9.2 & $4.58 \pm 0.46$ \\
10.6 & $4.61 \pm 0.36$ \\
12.0 & $4.63 \pm 0.45$ \\
\hline
\end{tabular}

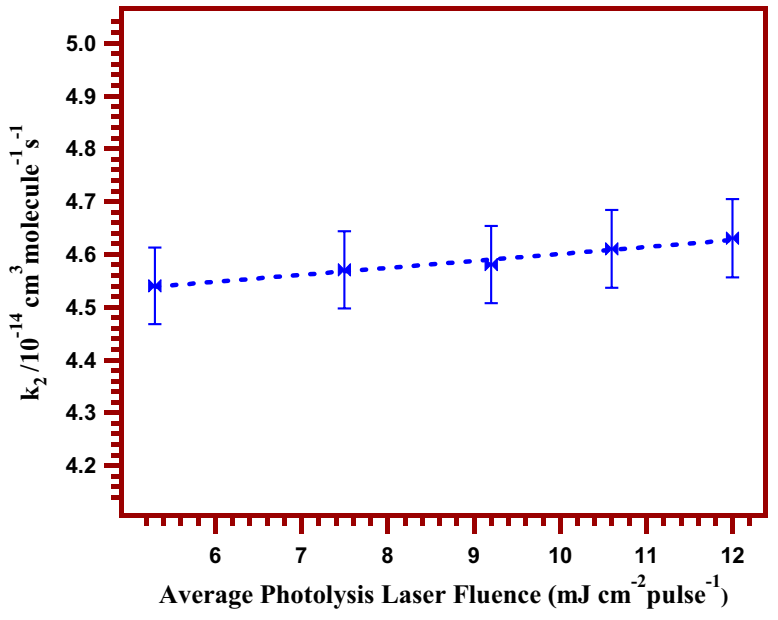

Fig. 5 The variation of rate coefficients for the reaction of phenyl radical with EF with the photolysis laser fluences at $298 \mathrm{~K}$ and 61 Torr of total pressure. At $2 \mathrm{~Hz}$, the average photolysis laser fluences were varied from 5.3 to $12.0 \mathrm{~mJ} \mathrm{~cm}$ pulse $^{-1}$. The dashed line indicates a linear fit

in the temperature range of 200-400 K. Figure 6 shows the optimized geometries of the reactants, RCs, TSs and products obtained at B3LYP/6-31+G(d,p) level of theory. The corresponding cartesian coordinates and normal-mode harmonic frequencies have been tabulated in the SI (Table S2 and S3).

As shown in Scheme 1, there are six possible $\mathrm{H}$ abstraction sites in EF for phenyl radicals. The TS as well the reaction pathway formed by the abstraction of the lone $\mathrm{H}(\mathrm{H} 1)$ attached to the carbonyl group, was denoted by TS1. From our calculations it is revealed that both the hydrogens in $-\mathrm{CH}_{2}(\mathrm{H} 2$ and $\mathrm{H} 3)$ are equivalent in terms of the formed TS's energies. Hence, the TSs as well as the reaction pathways obtained by the abstraction of $\mathrm{H} 2$ and $\mathrm{H} 3$ are equivalent and were denoted by TS2 throughout the course of these calculations. Among the three methyl hydrogens (H4, H5 and H6), H4 was found to give distinct MEP and the corresponding TS as well as the reaction pathway is denoted by TS3. The hydrogens, H5 and H6 were found to be equivalent in terms of abstraction by phenyl radical. Therefore, the TSs and the reaction pathway formed by the abstraction of both H5 and H6, are denoted by TS4, unless otherwise specified. The pre-reactive complexes were found to be absent for TS3 and TS4, whereas the TS1 and TS2 were formed via the pre-reactive complexes, $\mathrm{RC} 1$ and $\mathrm{RC} 2$ respectively. The products formed from the $\mathrm{H}$ abstraction in $\mathrm{EF}$ were $\mathrm{P} 1, \mathrm{P} 2$, $\mathrm{P} 3$ and $\mathrm{P} 4$ which were formed from the corresponding TS1, TS2, TS3 and TS4 respectively. In all of the cases, benzene $\left(\mathrm{C}_{6} \mathrm{H}_{6}\right)$ was obtained as a common by-product. The $\mathrm{RC}$ formation was not observed for the TS3 and TS4 pathways as these pathways have quite high activation barriers (11.48 and $5.63 \mathrm{kcal} \mathrm{mol}^{-1}$ respectively). Even if the reactants come 

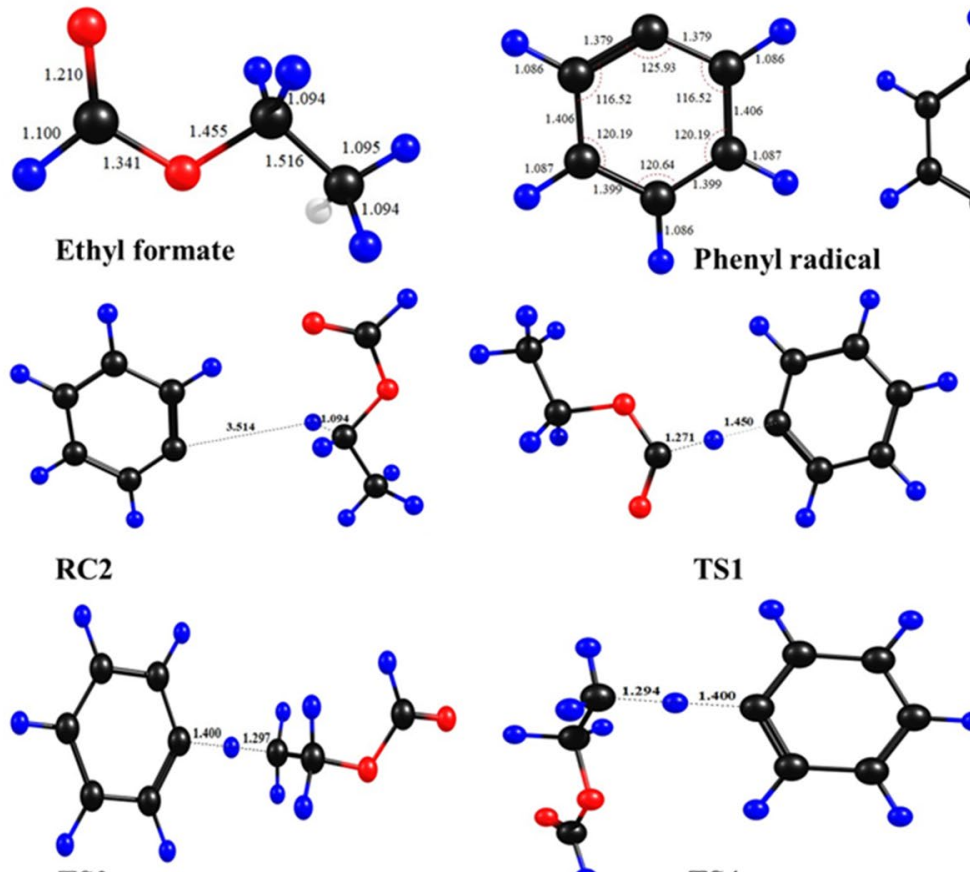

TS3

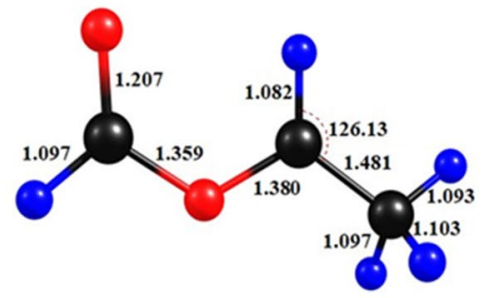

P2
TS1
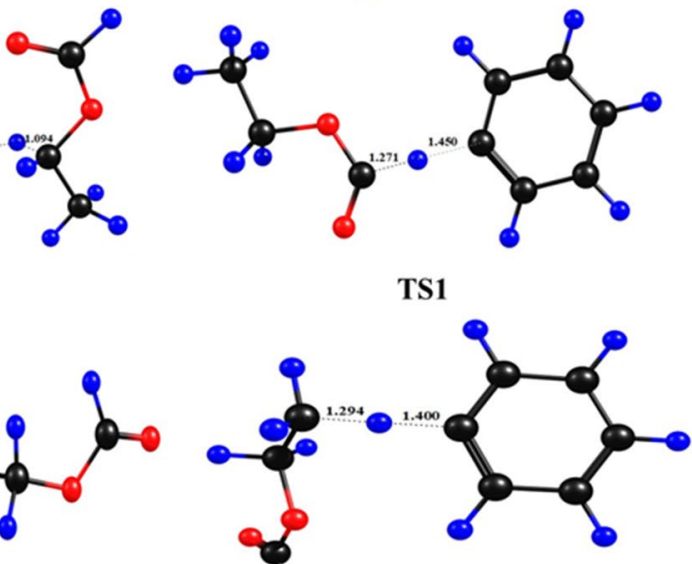

TS4

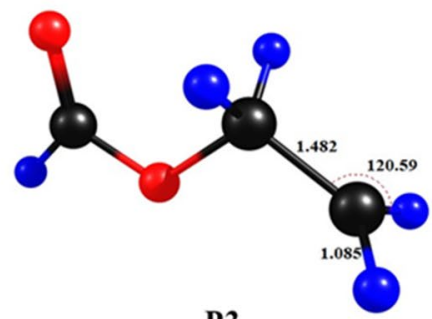

P3

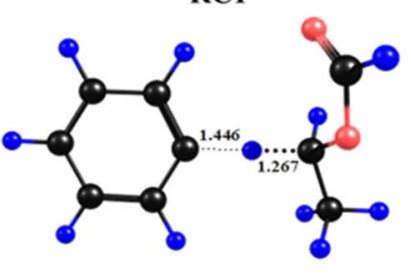

TS2

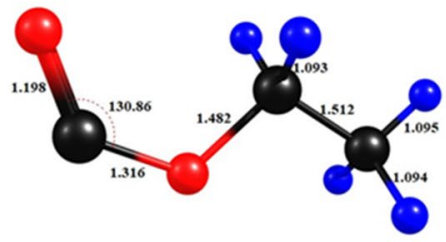

P1

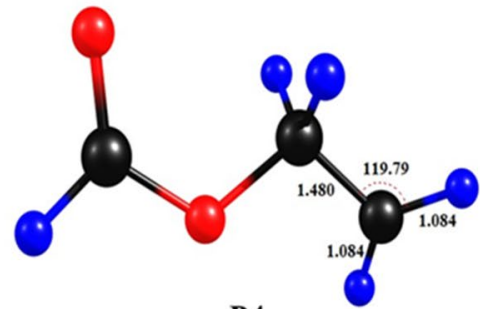

P4

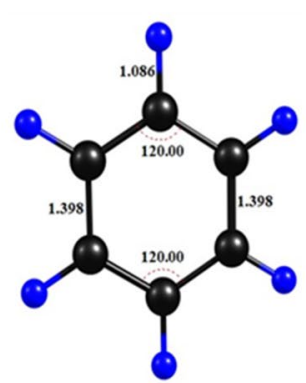

$\mathrm{C}_{6} \mathrm{H}_{6}$

Fig. 6 Optimized geometries of the reactants, pre-reactive complexes (RCs), transition states (TSs) and products (Ps) for the reaction of phenyl radicals with EF obtained at B3LYP/6-31+G(d,p) level of

closer due to van der Waals' force of attraction, the formed RCs can't have much collisional stabilization and hence a stabilized RC formation was not observed for the pathways having higher barrier heights i.e. TS3 and TS4.

Figure 7 shows the potential energy surface diagram for the title reaction obtained at $\operatorname{CCSD}(\mathrm{T}) / \mathrm{cc}-\mathrm{pVDZ} / /$ B3LYP/6-31 + G(d,p) level of theory. Only TS1 and TS2 proceed via the pre-reactive complexes ( $\mathrm{RC} 1$ and $\mathrm{RC} 2)$, with barrier heights of 3.33 and $2.42 \mathrm{kcal} \mathrm{mol}^{-1}$ respectively, theory. Black, blue and red colors indicate carbon, hydrogen and oxygen atoms respectively. The bond distances and bond angles have been represented in $\AA$ and degree respectively

whereas for TS3 and TS4 they are 11.48 and $5.63 \mathrm{kcal} \mathrm{mol}^{-1}$ respectively.

As there were four distinct reaction pathways (i.e., TS1, TS2, TS3 and TS4) for the $\mathrm{H}$ abstraction by phenyl radical over EF, the overall rate coefficient for the reaction (phenyl radical $+\mathrm{EF}$ ) at a particular temperature was calculated by summing up the weighted contributions of the rate coefficients corresponding to the individual pathways, as follows- 


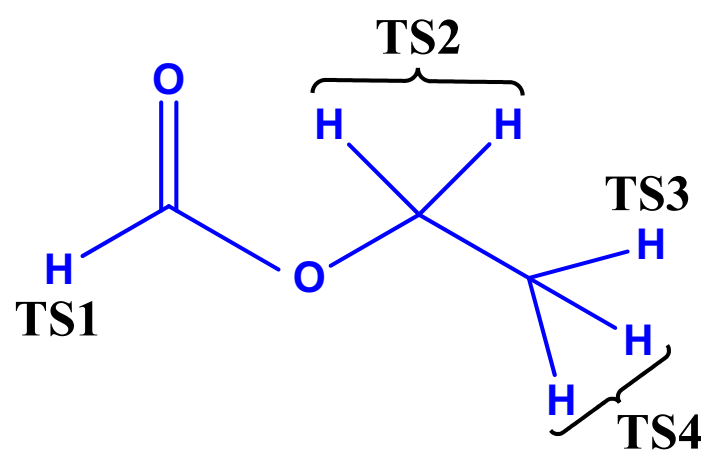

Scheme 1 Possible $\mathrm{H}$ abstraction sites and distinct reaction pathways in EF for the reaction with phenyl radicals

$\mathrm{k}_{\mathrm{tot}}(\mathrm{T})=\mathrm{k}_{\mathrm{TS} 1}+2 \mathrm{k}_{\mathrm{TS} 2}+\mathrm{k}_{\mathrm{TS} 3}+2 \mathrm{k}_{\mathrm{TS} 4}$

In TS1 and TS2, the \% elongation in the respective C-H bond lengths was 17.1 and 17.3, whereas it was 20.2 and 20.3 for TS3 and TS4, respectively. L parameters [39] for all the reaction pathways were calculated to predict whether a TS exhibit reactant or a product like character and are depicted in Table 4.

The L-parameters for TS1, TS2, TS3 and TS4 were calculated to be $0.49,0.48,0.64$ and 0.64 , respectively. As all the L-parameter values were calculated to be lesser than unity $(\mathrm{L}<1.0)$, all the TSs involved in the reaction of (phenyl radical $+\mathrm{EF}$ ) exhibit reactant-like character. Thus, according to Hammond's postulate [40], all the reaction channels -TS1, TS2, TS3 and TS4, will be exergonic in nature. In addition, thermochemical parameters were calculated for the title reaction at B3LYP/6-31+G(d,p) level of theory and are tabulated in Table 5. Among all the
Table 4 The calculated L-parameter values for the reaction between phenyl radicals and $\mathrm{EF}$ obtained at B3LYP/6-31+G(d,p) level of theory

\begin{tabular}{ll}
\hline Pathway & L-parameter \\
\hline TS1 & 0.49 \\
TS2 & 0.48 \\
TS3 & 0.64 \\
TS4 & 0.64 \\
\hline
\end{tabular}

Table 5 The calculated change in standard enthalpy $\left[\Delta \mathrm{H}^{0}(298 \mathrm{~K})\right]$ and Gibbs' free energy $\left[\Delta \mathrm{G}^{0}(298 \mathrm{~K})\right]$ for the reaction between phenyl radicals and $\mathrm{EF}$ at $\mathrm{B} 3 \mathrm{LYP} / 6-31+\mathrm{G}(\mathrm{d}, \mathrm{p})$ level of theory

\begin{tabular}{lcc}
\hline Pathway & $\begin{array}{l}\Delta \mathrm{H}^{0} \\
\mathrm{kcal} \mathrm{mol}^{-1}\end{array}$ & $\begin{array}{l}\Delta \mathrm{G}^{0} \\
\mathrm{kcal} \mathrm{mol}^{-1}\end{array}$ \\
\hline TS1 path & -13.71 & -13.83 \\
TS2 path & -16.13 & -16.45 \\
TS3 path & -10.09 & -9.68 \\
TS4 path & -10.00 & -10.59 \\
\hline
\end{tabular}

reaction pathways, TS2 was found to be the most exothermic $\left(\Delta \mathrm{H}^{0}=-16.13 \mathrm{kcal} \mathrm{mol}^{-1}\right)$ as well as the most feasible pathway $\left(\Delta \mathrm{G}^{0}=-16.45 \mathrm{kcal} \mathrm{mol}^{-1}\right)$.

The CVT/SCT rate coefficients for the reaction between phenyl radicals and EF were computed at $\operatorname{CCSD}(\mathrm{T}) / \mathrm{cc}$ pVDZ//B3LYP/6-31+ G(d,p) in the temperatures between 200 and $400 \mathrm{~K}$ and are depicted in Table 6 . The low frequency 1-D internal rotational modes were treated with hindered rotor approximation by McClurg et al. [41]. All the remaining vibrations were treated harmonically. At room temperature, the rate coefficient for the title reaction was calculated to be $\mathrm{k}_{\text {phenyl+EF }}^{\text {Theory,298K }}=4.91 \times 10^{-14} \mathrm{~cm}^{3}$ molecule $\mathrm{s}^{-1} \mathrm{~s}^{-1}$. The theoretically calculated rate coefficients were fitted by a modified Arrhenius equation [Eqn. (7)] and are depicted in Fig. 8. The $\mathrm{T}$ dependent Arrhenius expression for the reaction of (phenyl
Fig. 7 The potential energy surface diagram obtained for the reaction of phenyl radicals with $\mathrm{EF}$ at $\mathrm{CCSD}(\mathrm{T}) / \mathrm{cc}-\mathrm{pVDZ} / /$ B3LYP/6-31+G(d,p) level of theory at $298 \mathrm{~K}$. The numbers in parenthesis indicate relative energies (in kcal mol${ }^{-1}$ ) of the pre-reactive complexes (RCs), transition states (TSs) and products $(\mathrm{Ps})$

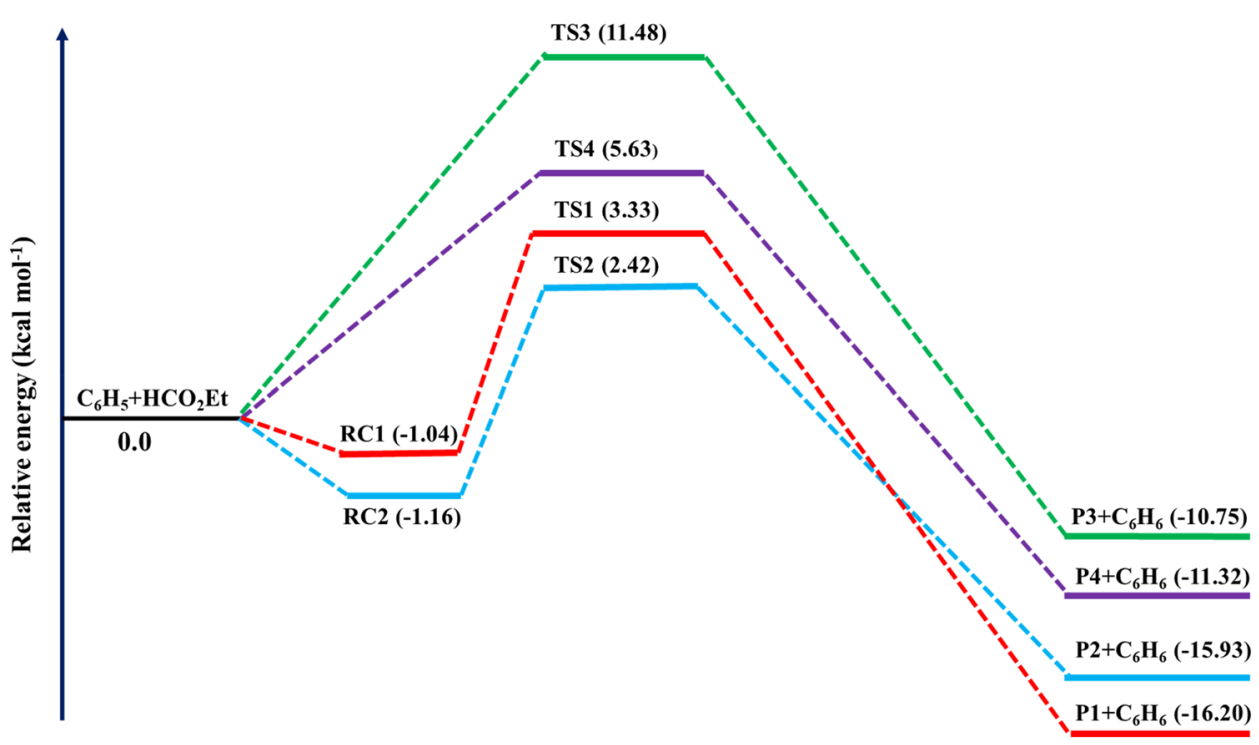


Table 6 The computed CVT/SCT rate coefficients for the reaction of (phenyl radical + EF) at CCSD $(\mathrm{T}) / \mathrm{cc}-\mathrm{pVDZ} / / \mathrm{B} 3 \mathrm{LYP} / 6-31+\mathrm{G}(\mathrm{d}, \mathrm{p})$ in the temperatures between 200 and $400 \mathrm{~K}$

\begin{tabular}{|c|c|}
\hline $\begin{array}{l}\text { Temperature } \\
(\mathrm{K})\end{array}$ & $\begin{array}{l}\mathrm{k}(\text { Theory) } \\
\left(\mathrm{cm}^{3} \text { molecule }{ }^{-1} \mathrm{~s}^{-1}\right)\end{array}$ \\
\hline 200 & $9.37 \times 10^{-14}$ \\
\hline 225 & $5.93 \times 10^{-14}$ \\
\hline 250 & $4.99 \times 10^{-14}$ \\
\hline 275 & $4.80 \times 10^{-14}$ \\
\hline 298 & $4.91 \times 10^{-14}$ \\
\hline 300 & $4.95 \times 10^{-14}$ \\
\hline 325 & $5.26 \times 10^{-14}$ \\
\hline 350 & $5.71 \times 10^{-14}$ \\
\hline 375 & $6.32 \times 10^{-14}$ \\
\hline 400 & $7.02 \times 10^{-14}$ \\
\hline
\end{tabular}

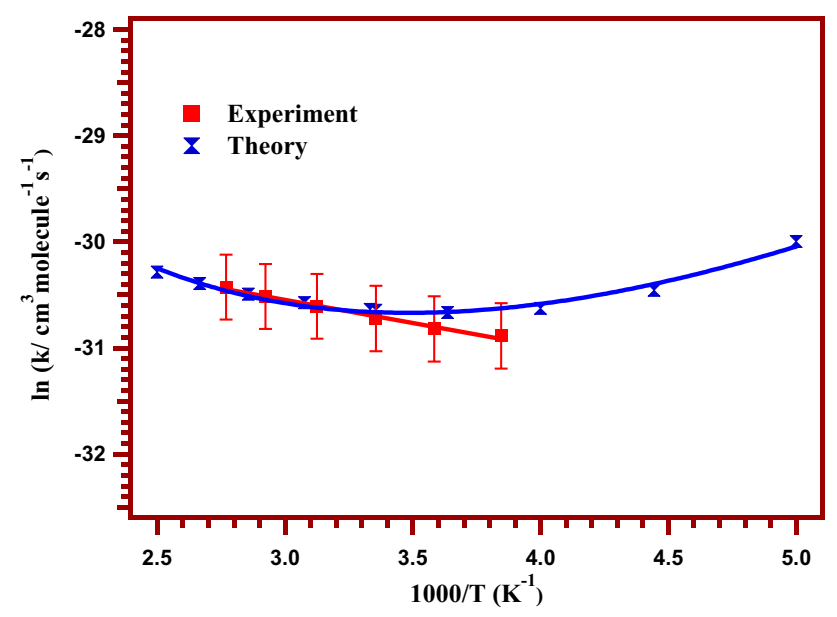

Fig. 8 Arrhenius plot of experimentally measured rate coefficients between 260 and $361 \mathrm{~K}$ using CRDS and the computed CVT/SCT rate coefficients at $\mathrm{CCSD}(\mathrm{T}) / \mathrm{cc}-\mathrm{pVDZ} / \mathrm{B} 3 \mathrm{LYP} / 6-31+\mathrm{G}(\mathrm{d}, \mathrm{p})$ level of theory between 200 and $400 \mathrm{~K}$, for the reaction of phenyl radicals with $\mathrm{EF}$

radical $+\mathrm{EF}$ ) between the temperatures 200 and $400 \mathrm{~K}$, was obtained as-

$$
\begin{aligned}
& \mathrm{k}_{\mathrm{phenyl}+\mathrm{EF}}^{\text {Theory } 200-400 \mathrm{~K}} \\
& =(1.48 \pm 0.56) \times 10^{-38} \\
& \quad \times \mathrm{T}^{8.47} \times \exp \left[\frac{(2431.3 \pm 322.0)}{\mathrm{T}}\right] \mathrm{cm}^{3} \text { molecule }^{-1} \mathrm{~s}^{-1}
\end{aligned}
$$

\subsection{Kinetic analysis}

At room temperature, the experimentally measured and theoretically calculated rate coefficients for the reaction of (phenyl radical $+E F$ ) are $\mathrm{k}_{\text {phenyl+EF }}^{\text {Expt } 298 \mathrm{~K}}=(4.54 \pm 0.42) \times 10^{-14} \mathrm{~cm}^{3}$ molecule ${ }^{-1} \mathrm{~s}^{-1}$ and $\mathrm{k}_{\text {phenyl+EF }}^{\text {Theory,298K }}=4.91 \times 10^{-14} \mathrm{~cm}^{3}$ molecule ${ }^{-1} \mathrm{~s}^{-1}$ respectively. The deviation of the theoretically calculated rate coefficient of the test reaction from the experimentally measured one at room temperature, was found to be only $8 \%$ which falls well within the experimental uncertainties itself. And therefore, we are confident to say that a very good agreement was found between the experimentally measured and theoretically calculated rate coefficients at $298 \mathrm{~K}$.

A positive and linear temperature dependency was detected for the experimentally measured rate coefficients of the reaction of (phenyl radical $+\mathrm{EF}$ ) in the temperatures between 260 and $361 \mathrm{~K}$. As seen from Fig. 8, the experimentally measured rate coefficients show very good agreement with the theoretically calculated ones and the agreement was found to be much better at higher temperatures whereas, at lower temperatures, especially between 250-300 K, the agreement between these two was comparatively low. Although the experimentally measured rate coefficients show a positive $\mathrm{T}$ dependency throughout the studied temperature range, the theoretically calculated rate coefficients show positive $\mathrm{T}$ dependency above $300 \mathrm{~K}$ only. Between 250-300 K, the theoretically calculated rate coefficients of the title reaction show a very weak and non-linear negative temperature dependency which can partly be ascribed to the formation of the stabilized pre-reactive complexes. This can partially be attributed to the higher degree of influence of the temperature-dependent tunneling factor to the overall rate coefficient in the low-temperature regimes, especially between 200 and $300 \mathrm{~K}$. A proper identification of the stabilized RCs for two of the kinetically most contributing pathways (i.e., TS1 and TS2) in the title reaction, avoided the underestimation of the tunneling factor for low barrier pathways and enabled us for a more accurate rate coefficient calculation. Moreover, low degree of agreement of experimentally measured and theoretically calculated rate coefficients between 250-300 K, can also be attributed to the choice of theories and basis sets as well as to the partition functions of the reactants and TSs. With the increase in temperature, especially beyond $300 \mathrm{~K}$, the experimentally measured and theoretically calculated rate coefficients showed excellent agreement and both of them showed a positive temperature dependency.

The experimentally measured rate coefficient for the reaction of (phenyl radical $+E F$ ) was found to be $\sim 2$ times higher than that for the reaction of phenyl radicals with ethyl acetate (EA; EtOAc) $\left[\mathrm{k}_{\text {phenyl+EA }}^{\text {Expt } 298 \mathrm{~K}}=(2.20 \pm 0.23) \times 10^{-14} \mathrm{~cm}^{3} \text { molecule }{ }^{-1} \mathrm{~s}^{-1}\right]^{18}$ at room temperature. At room temperature, the higher reactivity towards phenyl radicals for EF compared to EA can be attributed to the greater stability of the product radical species [i.e., $\mathrm{HCO}_{2}(\mathrm{CH}) \mathrm{CH}_{3}$ ] formed upon $\mathrm{H}$ atom abstraction 
from EF. It is because of the extended conjugation of the radical centre with the lone pair of electrons on the adjacent oxygen atom and also the electron deficient radical centre is stabilized by the electron-donating inductive effect $(+\mathrm{I})$ exerted by the adjacent $-\mathrm{CH}_{3}$ moiety. Whereas the product radical species which is majorly formed from EA [i.e., $\left.\left(\mathrm{CH}_{2}\right) \mathrm{CO}_{2} \mathrm{Et}\right]$ upon $\mathrm{H}$ abstraction at $298 \mathrm{~K}$, is destabilized due to the electron-withdrawing inductive effect (-I) exerted by the adjacent carbonyl moiety. In addition, a considerable amount of steric hindrance is exerted by the two bulky methyl groups in EA. Therefore the approach of phenyl radical will be more difficult in EA compared to that of EF which is only having one methyl substituent. Hence, it explains the higher reactivity of EF towards phenyl radicals compared to that of EA at room temperature.

\subsection{Branching ratio calculation and analysis}

The branching ratios (BRs) were calculated for the title reaction to examine the influence of an individual reaction pathway $\left(\mathrm{k}_{\mathrm{i}}\right)$ to the overall rate coefficient $\left(\mathrm{k}_{\mathrm{tot}}\right)$, as-

$\mathrm{BR}_{\mathrm{i}}(\mathrm{T}, \%)=\frac{\mathrm{k}_{\mathrm{i}}}{\mathrm{k}_{\mathrm{tot}}} \times 100$

The BRs were calculated for all the four reaction pathways (via TS1, TS2, TS3 and TS4) involved in the reaction of (phenyl radical $+\mathrm{EF}$ ) in the temperature range of 200-400 K at CCSD(T)/cc-pVDZ//B3LYP/6-31+ G(d,p) level of theory.

The calculated temperature-dependent BRs are tabulated in Table 7 and depicted in Fig. 9. At room temperature, the BRs for the respective pathways, i.e. TS1, TS2, TS3 and TS4 were calculated to be $21.2 \%, 79.03 \%, \sim 0 \%$ and $0.9 \%$, respectively. Hence, from BR calculations, it can be inferred that TS2 is the kinetically most labile pathway followed by TS1. BRs were found to be negligible for the pathways TS3 and TS4 compared to that of TS2 and TS1. As seen in Fig. 9, with the increase in temperatures between 200 and $400 \mathrm{~K}$, the BRs for TS2 were found to be increasing rapidly with temperature and becomes steady beyond $325 \mathrm{~K}$, whereas the same for TS1 was found to decrease sharply with temperature while achieving near constancy beyond $325 \mathrm{~K}$. Throughout the studied range, the \% BRs corresponding to the pathways TS3 and TS4 showed very weak temperature dependency compared to the TS1 and TS2 pathways.

The reaction pathway via TS2 was found to be thermodynamically the most feasible as well as kinetically the most labile pathway for the reaction of (phenyl radical $+\mathrm{EF}$ ). Abstraction of the $-\mathrm{CH}_{2}$ hydrogen by phenyl radical, leads to the generation of a secondary radical, i.e., $\mathrm{H}(\mathrm{CO})$ $\mathrm{OCHCH}_{3}$. This radical obtained from TS2, is stabilized by three hyper conjugative structures because of the presence
Table 7 The \% branching ratios (BRs) for the reaction of phenyl radicals with EF over the temperature range of $200-400 \mathrm{~K}$

\begin{tabular}{lllll}
\hline $\begin{array}{l}\text { Temperature } \\
(\mathrm{K})\end{array}$ & BR $(\%)$ & & & \\
\cline { 2 - 5 } & TS1 & TS2 & TS3 & TS4 \\
\hline 200 & 64.57 & 35.38 & $1.27 \times 10^{-6}$ & $5.32 \times 10^{-2}$ \\
225 & 44.50 & 55.40 & $5.45 \times 10^{-6}$ & $9.54 \times 10^{-2}$ \\
250 & 32.15 & 67.71 & $1.78 \times 10^{-5}$ & $1.32 \times 10^{-1}$ \\
275 & 25.13 & 74.71 & $5.03 \times 10^{-5}$ & $1.61 \times 10^{-1}$ \\
298 & 21.19 & 78.63 & $1.18 \times 10^{-4}$ & $1.85 \times 10^{-1}$ \\
300 & 20.85 & 78.97 & $1.26 \times 10^{-4}$ & $1.86 \times 10^{-1}$ \\
325 & 18.27 & 81.52 & $2.85 \times 10^{-4}$ & $2.09 \times 10^{-1}$ \\
350 & 16.66 & 83.11 & $5.92 \times 10^{-4}$ & $2.29 \times 10^{-1}$ \\
375 & 15.53 & 84.22 & $1.13 \times 10^{-3}$ & $2.47 \times 10^{-1}$ \\
400 & 14.80 & 84.93 & $2.03 \times 10^{-3}$ & $2.65 \times 10^{-1}$ \\
\hline
\end{tabular}

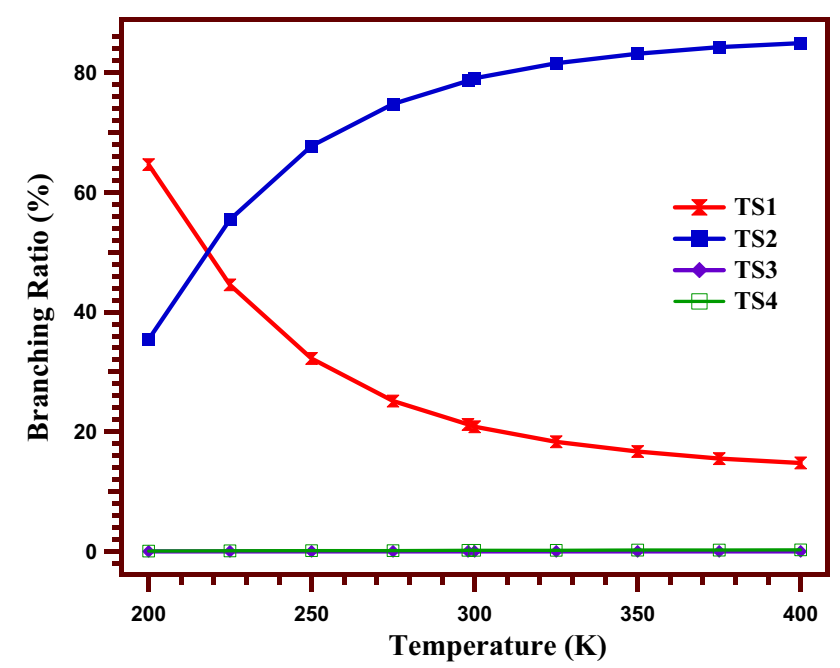

Fig. 9 The variation of $\%$ branching ratio for all the pathways involved in the reaction of (phenyl radical $+\mathrm{EF}$ ) over the temperature range of 200 to $400 \mathrm{~K}$, obtained at $\mathrm{CCSD}(\mathrm{T}) / \mathrm{cc}-\mathrm{pVDZ} / \mathrm{B} 3 \mathrm{LYP} / 6-$ $31+\mathrm{G}(\mathrm{d}, \mathrm{p})$ level of theory

of the adjacent methyl group. Additional stability of thus formed $2^{\circ}$ radical also originates from the electron-donating resonating effect $(+\mathrm{R})$ exerted by the lone pair of electrons on the adjacent oxygen atom. Hence, it explains both the thermodynamic feasibility as well as the kinetic lability of the reaction pathway via TS2 for the title reaction.

At low temperatures, preferably below $250 \mathrm{~K}$, the contribution of TS1 pathway to the total rate coefficient was found to be quite significant. Furthermore, below $225 \mathrm{~K}$, TS1 reaction pathway was found to be having higher $\%$ BR compared to that of TS2 pathway and \% BR starts decreasing from $225 \mathrm{~K}$ with an increase in the temperature and beyond $300 \mathrm{~K}$, it reaches a near constancy. Abstraction of the $\mathrm{H}$ attached to the carbonyl group of EF, by phenyl radical, leads to the 
formation of a primary radical, i.e., $\left[(\mathrm{CO}) \mathrm{OCH}_{2} \mathrm{CH}_{3}\right]$ which is devoid of any hyper conjugative stability like the secondary radical $\left[\mathrm{H}(\mathrm{CO}) \mathrm{O}^{-} \mathrm{CHCH}_{3}\right]$ which is generated from the TS2 pathway. The primary radical formed via TS1 pathway is stable due to the electron-donating resonating effect $(+R)$ exerted by the lone pair of electrons over the adjacent oxygen atom. At low temperatures, especially below $225 \mathrm{~K}$, the primary radical formation via TS1 pathway dominates for the title reaction of (phenyl $+\mathrm{EF}$ ). It is primarily due to the greater acidity of the $\mathrm{H}$ attached directly to electron-withdrawing carbonyl group and moreover, the approach of the phenyl radical is not sterically hindered too. As the temperature increases, hyperconjugation effect and $+\mathrm{I}$ effect dominates in the secondary radical (TS2 path) over the $+\mathrm{R}$ effect in the primary radical (TS1 path), which makes TS2 reaction pathway more dominant. Therefore, the secondary radical starts to get higher yields and the TS2 pathway starts dominating.

In case of the reaction of phenyl radicals with ethyl acetate (EA) [17], the $\mathrm{H}$ abstraction from the $\alpha$-methyl group attached to the carbonyl of EA, by phenyl radicals, were found to be kinetically the most labile pathway. The percentage BR of this pathway was found to be hovering between 96.1-99.9 throughout the studied temperature range of 200-400 K. BR of all other pathways were found to be negligible compared to this pathway. Although, $\mathrm{H}$ abstraction from the $-\mathrm{CH}_{2}$ group of EA, by phenyl radicals, were found to be thermodynamically the most feasible pathway. No significant temperature dependency of the BR for any of the pathways for the reaction of (phenyl +EA) was observed. The $\mathrm{H}$ abstraction from the $\alpha$-methyl group in EA by phenyl radical, leads to the formation of $\left(\mathrm{CH}_{2} \mathrm{CO}_{2} \mathrm{Et}\right)$ radical which is stabilized by resonance with the adjacent carbonyl and lone pair of electrons over oxygen atom. This radical is also stabilized by the electron-donating inductive effect $(+\mathrm{I})$ exerted by the ethyl group. The approach of the phenyl radical is highly sterically hindered due to the presence of two bulky methyl groups on the two ends of EA, therefore it predominantly abstracts $\alpha$-methyl H's because of their enhanced acidity due to the presence of strong electron-withdrawing inductive effect (-I) of the carbonyl group. Strong steric repulsion as well as weak acidity of the H's in the $-\mathrm{OCH}_{2} \mathrm{CH}_{3}$ moiety in EA, leads to a hindered phenyl radical approach and in turn, explains the low BR contribution of the other pathways in (phenyl $+\mathrm{EA}$ ) reaction. Because of the low \% yield of the radicals from the other pathways, the concentration of $\mathrm{CH}_{2} \mathrm{CO}_{2} \mathrm{Et}$ radical stays more or less constant throughout the temperature range of 200-400 $\mathrm{K}$ and no significant deviation of branching ratios with respect to the temperatures for any of the pathways is observed for the reaction of (phenyl+EA).

Therefore, the most labile pathway was found to be $\mathrm{H}$ atom abstraction by phenyl radical from the alpha $(\alpha)$ carbon of EA and from the methylene $\left(-\mathrm{CH}_{2}\right)$ carbon in EF, whereas in both the cases, $\mathrm{H}$ abstraction from the methylene carbon by phenyl radical, was found to be thermodynamically the most feasible pathway.

\section{Conclusion}

The kinetics for the reaction between phenyl radicals and EF were investigated experimentally in the gas phase between 260 and $361 \mathrm{~K}$ at a total pressure of 61 Torr with $\mathrm{N}_{2}$ using CRDS. The rate coefficients were found to be independent of experimental pressures and photolysis laser fluences for the studied range. In addition, the kinetics of the title reaction was investigated theoretically in the temperature range of 200-400 K using CVT/SCT methodology at CCSD(T)/cc-pVDZ// B3LYP/6-31+G(d,p) level of theory. The experimentally measured and theoretically calculated rate coefficients show a very good agreement with each other at room temperature. Both experimentally measured and theoretically calculated kinetics of the reaction of (phenyl radical $+\mathrm{EF}$ ) shows a positive temperature dependency. At room temperature, the reactivity of EF towards phenyl radicals was found to be two times higher compared to that of EA. The abstraction of $-\mathrm{CH}_{2}$ hydrogen in EF by phenyl radical was found to be thermodynamically the most feasible as well as kinetically the most labile pathway. The most kinetically labile pathway was found to be $\mathrm{H}$ atom abstraction by phenyl radical from the $\alpha$-carbon of EA and from the methylene $\left(-\mathrm{CH}_{2}\right)$ group in EF, whereas in both the cases, $\mathrm{H}$ abstraction from $-\mathrm{CH}_{2}$ by phenyl radical, was found to be thermodynamically the most feasible pathway. Below $275 \mathrm{~K}$, the theoretically calculated rate coefficients of the title reaction showed a very weak and non-linear negative temperature dependency and the agreement with the experimentally measured rate coefficients were found to be comparatively lower, whereas an excellent agreement between the two was observed at temperatures higher than $275 \mathrm{~K}$. Hence further experimental investigation of the kinetics of the title reaction needs to be performed in the ultracold temperatures, especially below $260 \mathrm{~K}$, to better understand its low-temperature behaviour and to arrive at an overall picture.

Supplementary Information The online version contains supplementary material available at https://doi.org/10.1007/s43630-021-00053-7.

Acknowledgements The authors thank the Central Electronics Centre and Central Workshop Facility of IIT Madras for their support. We also thank High Performance Computing Environment facility at IIT Madras for providing the VIRGO supercluster using which all the computational calculations were performed. We acknowledge SERB, Government of India, for the monetary support. 


\section{Declarations}

Conflict of interest On behalf of all authors, the corresponding author states that there is no conflict of interest.

\section{References}

1. Frenklach, M. (2002). Reaction mechanism of soot formation in flames. Physical Chemistry Chemical Physics, 4, 2028-2037.

2. Richter, H., \& Howard, J. B. (2000). Formation of polycyclic aromatic hydrocarbons and their growth to soot-A review of chemical reaction pathways. Progress in Energy and Combustion Science, 26, 565-608.

3. Richter, H., \& Howard, J. B. (2002). Formation and consumption of single-ring aromatic hydrocarbons and their precursors in premixed acetylene, ethylene and benzene flames. Physical Chemistry Chemical Physics, 4, 20-2055.

4. Miller, J. A., Pilling, M. J., \& Troe, J. (2005). Unravelling combustion mechanisms through a quantitative understanding of elementary reactions. Proceedings of the Combustion Institute, $30,43-88$.

5. Durant, J. L., Busby, W. F., Jr., Lafleur, A. L., Penman, B. W., \& Crespi, C. L. (1996). Human cell mutagenicity of oxygenated, nitrated and unsubstituted polycyclic aromatic hydrocarbons associated with urban aerosols. Mutation Research/Genetic Toxicology, 371, 123-157.

6. Samanta, S. K., Singh, O. V., \& Jain, R. K. (2002). Polycyclic aromatic hydrocarbons: Environmental pollution and bioremediation. Trends in Biotechnology, 20, 243-248.

7. Menzie, C. A., Potocki, B. B., \& Santodonato, J. (1992). Exposure to carcinogenic PAHs in the environment. Environmental Science and Technology, 26, 1278-1284.

8. Calvert, J. G., Atkinson, R., Becker, K. H., Kamens, R. M., Seinfeld, J. H., Wallington, T. J., \& Yarwood, G. (2002). Mechanisms of atmospheric oxidation of aromatic hydrocarbons. Oxford University Press.

9. Glassman, I., Yetter, R. A., \& Glumac, N. G. (2014). Combustion. Academic press.

10. Yee, L. D., Craven, J. S., Loza, C. L., Schilling, K. A., Ng, N. L., Canagaratna, M. R., Ziemann, P. J., Flagan, R. C., \& Seinfeld, J. H. (2012). Secondary organic aerosol formation from low-NO $\mathrm{x}$ photooxidation of dodecane: Evolution of multigeneration gasphase chemistry and aerosol composition. The Journal of Physical Chemistry A, 116(24), 6211-6230.

11. Hill, J., Nelson, E., Tilman, D., Polasky, S., \& Tiffany, D. (2006). Environmental, economic, and energetic costs and benefits of biodiesel and ethanol biofuels. Proceedings of the National Academy of Sciences of the United States of America, 103(30), 11206-11210.

12. Ivanov, B., \& Stoyanov, S. (2016). A mathematical model formulation for the design of an integrated biodiesel-petroleum diesel blends system. Energy, 99, 221-236.

13. Prueksakorn, K., Gheewala, S. H., Malakul, P., \& Bonnet, S. (2010). Energy analysis of Jatropha plantation systems for biodiesel production in Thailand. Energy for Sustainable Development, 14(1), 1-5.

14. Coniglio, L., Bennadji, H., Glaude, P. A., Herbinet, O., \& Billaud, F. (2013). Combustion chemical kinetics of biodiesel and related compounds (methyl and ethyl esters): Experiments and modeling-advances and future refinements. Progress in Energy and Combustion Science, 39(4), 340-382.

15. Belloche, A., Garrod, R., Müller, H., Menten, K., Comito, C., \& Schilke, P. (2009). Increased complexity in interstellar chemistry:
Detection and chemical modeling of ethyl formate and n-propyl cyanide in sagittarius B2 (N). Astronomy and Astrophysics, 499(1), 215-232.

16. Mondal, K., Kaipara, R., \& Rajakumar, B. (2019). Investigation of the absorption cross-section of phenyl radical and its kinetics with methanol in the gas phase using cavity ring-down spectroscopy and theoretical methodologies. The Journal of Physical Chemistry A, 123, 9682-9692.

17. Mondal, K., \& Rajakumar, B. (2020). Kinetic investigations of the reaction of phenyl radicals with ethyl acetate in the gas phase: An experimental and computational study. The Journal of Physical Chemistry A, 124, 5503-5512.

18. Tonokura, K., Norikane, Y., Koshi, M., Nakano, Y., Nakamichi, S., Goto, M., Hashimoto, S., Kawasaki, M., Sulbaek Andersen, M. P., Hurley, M. D., \& Wallington, T. J. (2002). Cavity ring-down study of the visible absorption spectrum of the phenyl radical and kinetics of its reactions with $\mathrm{Cl}, \mathrm{Br}, \mathrm{Cl}_{2}$ and $\mathrm{O}_{2}$. The Journal Physical Chemistry A, 106, 5908-5917.

19. Frisch, M. J., et al. (2016). Gaussian 16, revision B.01. Gaussian Inc.

20. Becke, A. D. (1993). A new mixing of Hartree-Fock and local density functional theories. The Journal of Chemical Physics, 98, 1372.

21. McLean, A. D., \& Chandler, G. S. (1980). Contracted Gaussianbasis sets for molecular calculations. 1 . Second row atoms, $\mathrm{Z}=11$ 18. The Journal of Chemical Physics, 72, 5639-5648.

22. Krishnan, R., Binkley, J. S., Seeger, R., \& Pople, J. A. (1980). Self-consistent molecular orbitals methods. 20. Basis set for correlated wave-functions. The Journal of Chemical Physics, 72, 650-654.

23. Dennington, R., Keith, T. A., \& Millam, J. M. (2016). GaussView, version 6 . Semichem Inc.

24. Jissy, A. K., \& Datta, A. (2013). Can Arsenates replace phosphates in natural biochemical processes? A computational study. The Journal of Physical Chemistry B, 117, 8340-8346.

25. Hratchian, H. P., Frisch, M. J., \& Schlegel, H. B. (2010). Steepest descent reaction path integration using a first-order predictor-corrector method. The Journal Chemical Physics, 133, 224101-224108.

26. Lee, T. J., \& Taylor, P. R. (1989). A diagnostic for determining the quality of single-reference electron correlation methods. International Journal of Quantum Chemistry, 36, 199-207.

27. Dunning, T. H. (1989). Gaussian basis sets for use in correlated molecular calculations. I. The atoms boron through neon and hydrogen. The Journal Chemical Physics, 90, 1007-1023.

28. Rodriguez, A., Rodriguez, D., Garzon, A., Soto, A., Aranda, A., $\&$ Notario, A. (2010). Kinetics and mechanism of the atmospheric reactions of atomic chlorine with 1-penten-3-ol and (Z)-2-penten1-ol: An experimental and theoretical study. Physical Chemistry Chemical Physics, 12, 12245-12258.

29. Galano, A., Munoz-Rugeles, L., Alvarez-Idaboy, J. R., Bao, J. L., \& Truhlar, D. G. (2016). Hydrogen abstraction reactions from phenolic compounds by peroxyl radicals: Multireference character and density functional theory rate constants. The Journal of Physical Chemistry A, 120, 4634-4642.

30. Gonzalez-Lafont, A., Truong, T. N., \& Truhlar, D. G. (1991). Interpolated variational transition state theory: Practical methods for estimating variational transition state properties and tunnelling contributions to chemical reaction rates from electronic structure calculations. The Journal of Chemical Physics, 95, 8875-8894.

31. Garrett, B. C., \& Truhlar, D. G. (1979). Generalized transition state theory. Classical mechanical theory and applications to collinear reactions of hydrogen molecules. The Journal of Chemical Physics, 83, 1052-1079.

32. Garrett, B. C., Truhlar, D. G., Grev, R. S., \& Magnuson, A. W. (1980). Improved treatment of threshold contributions in 
variational transition state theory. The Journal of Physical Chemistry, 84, 1730-1748.

33. Bao, J. L., \& Truhlar, D. G. (2017). Variational transition state theory: Theoretical framework and recent developments. Chemical Society Reviews, 46, 7548-7596.

34. Garrett, B. C., \& Truhlar, D. G. (2005). Variational transition state theory. (pp. 67-87). In theory and applications of computational chemistry.

35. Liu, Y. P., Lynch, G. C., Truong, T. N., Lu, D. H., Truhlar, D. G., \& Garrett, B. C. (1993). Molecular modelling of the kinetic isotope effect for the [1,5]-sigmatropic rearrangement of cis-1,3-Pentadiene. Journal of American Chemical Society, 115, 2408-2415.

36. Zheng, J., Zhang, S., Lynch, B. J., Corchado, J. C., Chuang, Y.-Y., Fast, P. L., Hu, W. P., Liu, Y. P., Lynch, G. C., Nguyen, K. A., et al. (2009). POLYRATE, version 2008. University of Minnesota.
37. Zheng, J., Zhang, S., Corchado, J. C., Chuang, Y.-Y., Coitiño, E. L., Ellingson, B. A., \& Truhlar, D. G. (2010). GAUSSRATE, version 2009-A. University of Minnesota.

38. Johnson, R. D., III., (2019). NIST Computational Chemistry Comparison and Benchmark Database; NIST Standard Database Number 101. National Institute of Standards and Technology: Gaithersburg, MD.

39. Rayez, M. T., Rayez, J. C., \& Sawerysyn, J. P. (1994). Ab initio studies of the reactions of chlorine atoms with fluoro- and chloro-substituted methanes. Journal of Physical Chemistry, 98, 11342-11352.

40. Hammond, G. S. (1955). A correlation of reaction rates. Journal of American Chemical Society, 77, 334-338.

41. McClurg, R. B., Flagan, R. C., \& Goddard, W. A. (1997). III. The hindered rotor density-of-states interpolation function. The Journal of Chemical Physics, 106, 6675-6680. 